\title{
Cognitive status of nurses in Shanghai on pulmonary rehabilitation
}

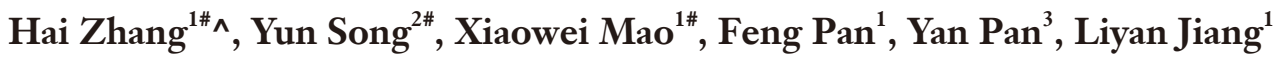 \\ ${ }^{1}$ Department of Pulmonary and Critical Care Medicine, Shanghai Chest Hospital, Shanghai Jiao Tong University, Shanghai, China; ${ }^{2}$ Department of \\ Thoracic Surgery, Shanghai Chest Hospital, Shanghai Jiao Tong University, Shanghai, China; ${ }^{3}$ Department of Pharmacy, Shanghai Chest Hospital, \\ Shanghai Jiao Tong University, Shanghai, China \\ Contributions: (I) Conception and design: L Jiang, Y Pan, H Zhang; (II) Administrative support: Y Song; (III) Provision of study materials or patients: \\ Y Song, H Zhang, X Mao; (IV) Collection and assembly of data: H Zhang, Y Song, F Pan; (V) Data analysis and interpretation: H Zhang, L Jiang, Y \\ Pan, X Mao; (VI) Manuscript writing: All authors; (VII) Final approval of manuscript: All authors. \\ \#These authors contributed equally to this work. \\ Correspondence to: Liyan Jiang. Department of Pulmonary and Critical Care Medicine, Shanghai Chest Hospital, Shanghai Jiao Tong University, \\ 241 West Huaihai Road, Shanghai 200030, China. Email: jiang_liyan2000@126.com; Yan Pan. Department of Pharmacy, Shanghai Chest Hospital, \\ Shanghai Jiao Tong University, 241 West Huaihai Road, Shanghai 200030, China. Email: sispan@126.com.
}

Background The nurse's specific understanding of pulmonary rehabilitation is not clear. The aim of the present study was to analyze the cognitive status of Shanghai nurses on pulmonary rehabilitation, and to provide a basis for the development of pulmonary rehabilitation work.

Methods: The cognitive status of pulmonary rehabilitation of nursing staff in Shanghai was investigated in the form of a questionnaire. The questionnaire included three main aspects of the function, content and indication of pulmonary rehabilitation, with 10 options for each aspect. The total score was 30 points, with 0-17 points indicating a low score and $18-30$ points indicating a high score.

Results: A total of 960 valid questionnaires were collected. The average score of pulmonary rehabilitation knowledge was 18.48 points, with a median of 19 [14-23] points. There were statistically significant differences in the total scores of pulmonary rehabilitation knowledge among nurses of different ages, types of hospitals, levels of hospitals, education levels, professional titles, positions, departments, and theoretical knowledge of pulmonary rehabilitation $(\mathrm{P}<0.05)$. There were no statistically significant differences in the scores among nurses of different sexes $(\mathrm{P}>0.05)$. The high-score group included age $\geq 40$ years $(79.5 \%)$, respiratory hospital $(71.7 \%)$, tertiary hospital $(65.5 \%)$, bachelor degree or above $(66.5 \%)$, nurse-in-charge or above $(77.9 \%)$, managerial position $(72.7 \%)$, pulmonary rehabilitation-related departments $(71.9 \%)$, and theoretical knowledge of lung rehabilitation (79.5\%). Logistic regression analysis showed that age, education level, professional title, discipline, and theoretical knowledge of lung rehabilitation were the main factors influencing the score of pulmonary rehabilitation knowledge of nursing staff in Shanghai $(\mathrm{P}<0.05)$.

Conclusions: More than half of the nurses surveyed in Shanghai scored high on the cognition of lung rehabilitation knowledge, but there were still many nurses who had poor theoretical knowledge of lung rehabilitation and had an insufficient understanding of the specific content of lung rehabilitation; therefore, there is room for improvement. More opportunities to develop understanding of pulmonary rehabilitation theory should be provided.

Keywords: Pulmonary rehabilitation; nurse; questionnaire

Submitted Dec 22, 2020. Accepted for publication Jan 04, 2021.

doi: 10.21037/apm-21-190

View this article at: http://dx.doi.org/10.21037/apm-21-190

$\wedge$ ORCID: 0000-0002-8705-6351. 


\section{Introduction}

Lung rehabilitation (or respiratory rehabilitation) is a comprehensive intervention measure based on comprehensive evaluation and is customized for patients, including, but not limited to, sports training, education, and behavioral change. The purpose of lung rehabilitation is to improve people's physical and psychological conditions, and promote long-term adherence to promote healthy behavior (1). Pulmonary rehabilitation is mainly aimed at patients with chronic obstructive pulmonary disease (COPD), as well as patients with other chronic respiratory diseases, such as pulmonary fibrosis and bronchial asthma. The interdisciplinary pulmonary rehabilitation team includes physicians, physiotherapists (exercise training experts), occupational therapists, psychological consultants, nutritionists, nurses, and social workers (2). Before pulmonary rehabilitation, a comprehensive assessment of patients is needed, which is conducted by a professional team. After the assessment, the professional team should formulate individual comprehensive intervention measures according to each patient's situation, such as exercise training, lifestyle changes, and respiratory rehabilitation education. Zhang et al. investigated the COPD rehabilitation knowledge of Shanghai rehabilitation professionals (3). The results showed that the level of rehabilitation practitioners was generally low, knowledge structure was unbalanced, and popularization of pulmonary rehabilitation knowledge was poor. Chen $e t$ al. investigated the level of pulmonary rehabilitation knowledge of respiratory physicians in Shanghai (4). The results showed that the level of knowledge of lung rehabilitation of respiratory physicians in Shanghai tertiary hospitals was low and popularization was poor. In the process of lung rehabilitation, nursing staff are an important link. The role of nursing staff is not only to nurse patients during hospitalization but also to help patients with lung rehabilitation, so that both hospitalized and discharged patients can benefit for a long time. Therefore, it is important for nursing staff to have basic knowledge of lung rehabilitation. However, the specific understanding of pulmonary rehabilitation among nurses is still unclear. Therefore, the aim of the present study was to evaluate the cognition of pulmonary rehabilitation knowledge among nurses in Shanghai and explore its influencing factors so as to provide more targeted health education on lung rehabilitation-related content, improve nurses' awareness of lung rehabilitation knowledge.
We present the following article in accordance with the SURGE reporting checklist (available at http://dx.doi. org/10.21037/apm-21-190).

\section{Methods}

\section{Participants}

Nursing staff of hospitals at all levels in Shanghai were used as the research participants. A total of 960 valid questionnaires were collected. All questionnaires were filled in anonymously. This study was conducted in accordance with the ethical principles of the World Medical Association's Declaration of Helsinki (as revised in 2013) and was approved by the Ethics Committee of Shanghai Chest Hospital (Ethics number: KS1924). Informed consent was obtained from all patients.

\section{Measurements}

In December 2019, Questionnaire Star software (https:// www.wjx.cn/,Changsha, Hunan, China) was used to send questionnaire links to nursing staff of hospitals at all levels in Shanghai through the WeChat platform. A self-made questionnaire was used. The questionnaire involved two main parts. The first part was on general information of the research participants (including sex, age, occupation, title, education, department, working years, and position). The second part was a cognitive-level investigation on the lung rehabilitation, including the function, content, and indications of lung rehabilitation, with 10 options. The total score of lung rehabilitation knowledge was 30 points, including 10 points for cognition of lung rehabilitation function, 10 points for cognition of lung rehabilitation content, and 10 points for cognition of lung rehabilitation indications. The total score of pulmonary rehabilitation knowledge was set $60 \%$ as the dividing line, with a score of $0-17$ indicating a low score and 18-30 indicating a high score.

\section{Statistical methods}

In the present study, Microsoft Excel 2016 was used to collate data and graphs. SPSS 25.0 software was used for data statistics and analysis. Non-normal distribution data were described by median and quartile, measurement data were expressed by mean \pm standard deviation, and counting data were described by frequency and percentage and analyzed by $\chi^{2}$-test. Multivariate analysis was used for the 
Table 1 General information of nursing staff $(n=960)$

\begin{tabular}{|c|c|c|}
\hline Factors & Groups & n (\%) \\
\hline Sex & Female & $939(97.8)$ \\
\hline \multirow[t]{2}{*}{ Age (years) } & $<30$ & $490(51.0)$ \\
\hline & $\geq 30,<40$ & $299(31.1)$ \\
\hline \multirow[t]{2}{*}{ Education } & College degree & $500(52.1)$ \\
\hline & Bachelor or above & $460(47.9)$ \\
\hline \multirow[t]{2}{*}{ Professional title } & Nurse & $340(35.4)$ \\
\hline & Nurse practitioner & $389(40.5)$ \\
\hline Position & Managerial position & $121(12.6)$ \\
\hline \multirow[t]{3}{*}{ Department } & Other Department & $481(50.1)$ \\
\hline & Internal or General Medicine & $255(26.6)$ \\
\hline & Pulmonary Rehabilitation-related Departments & $224(23.3)$ \\
\hline \multirow[t]{3}{*}{ Hospital type } & Other specialized hospitals & $250(26.0)$ \\
\hline & General hospital & $611(63.6)$ \\
\hline & Respiratory specialized hospital & $99(10.3)$ \\
\hline Hospital grade & 1st-level referral hospitals & $369(38.4)$ \\
\hline
\end{tabular}

binary logistic regression analysis. $\mathrm{P}<0.05$ indicated that the difference was statistically significant.

\section{Results}

\section{Shanghai nursing staff who accepted the questionnaire survey}

Among the 960 survey participants, 21 were male and 939 were females; 490 were younger than 30 years, 299 were 30 39 years, and 171 were $\geq 40$ years; 500 had a college degree and 460 had a bachelor degree or above; 340 were nurses, 389 were nurse practitioners, and 231 were nurses-in-charge or above; 839 had general positions and 121 had managerial positions; 224 worked in pulmonary rehabilitation-related disciplines (including respiratory medicine, thoracic surgery, and rehabilitation), 255 worked in general or internal medicine, and 481 worked in other disciplines; 99 worked in respiratory specialized hospitals, 611 in general hospitals, and 250 worked in other specialized hospitals; and 369 worked in first-level hospitals, 356 worked in second-level hospitals, and 235 worked third-level hospitals. A total of 219 had theoretical knowledge of pulmonary rehabilitation (Table 1).

\section{Scores of pulmonary rebabilitation knowledge}

The total score of pulmonary rehabilitation knowledge and the cognitive scores of the three parts are shown in Table 2. 
Table 2 Pulmonary rehabilitation effect, content, indication score, and total score ( $\mathrm{n}=960)$

\begin{tabular}{lccc}
\hline Items & Mean \pm standard deviation & Median (25-75\%) & High score (\%) \\
\hline Effects of lung rehabilitation & $7.91 \pm 2.413$ & $9[6-10]$ & $449(88.4)$ \\
Content of lung rehabilitation & $4.55 \pm 2.389$ & $4[0-9]$ & $418(43.5)$ \\
Indications of lung rehabilitation & $6.03 \pm 3.960$ & $6[4-8]$ & $532(55.4)$ \\
Total score of pulmonary rehabilitation knowledge & $18.48 \pm 5.920$ & $19[14-23]$ & $562(58.5)$ \\
\hline
\end{tabular}

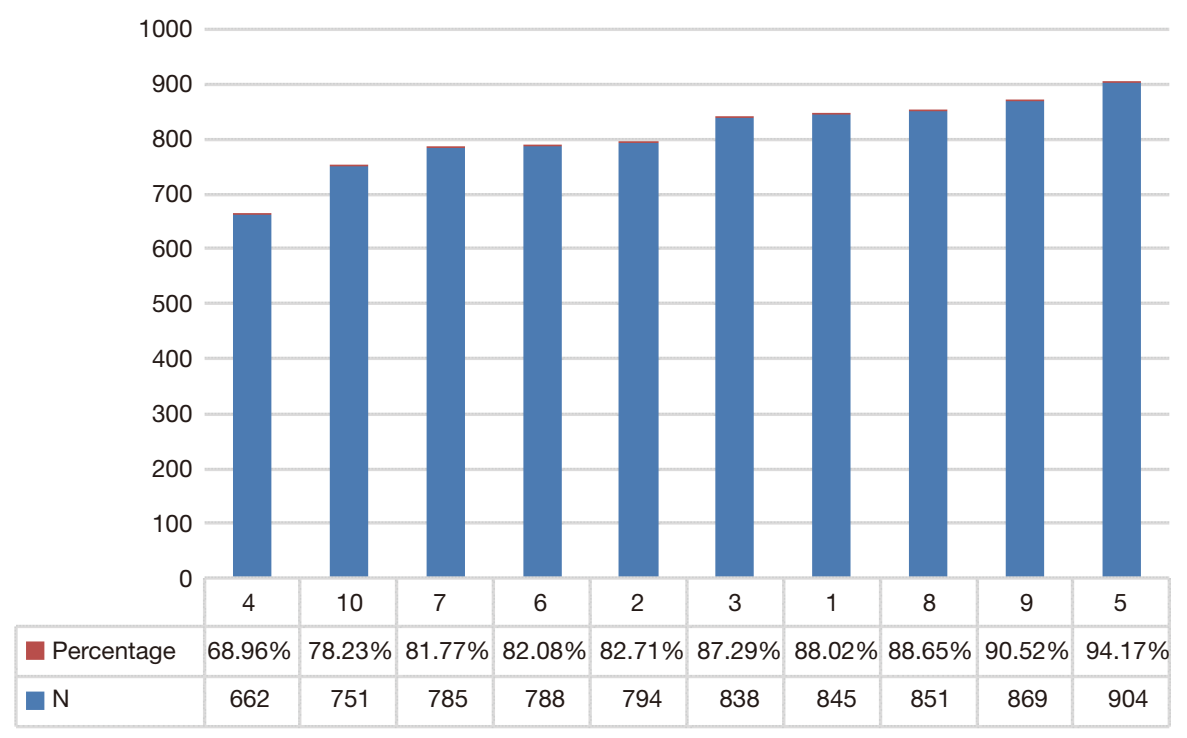

Figure 1 Number and percentage of correct cognition of lung rehabilitation effects among nurses in Shanghai. 1, reduce the hospitalization rate and mortality rate; 2 , limit exercise capacity; 3 , aggravate dyspnea and lower limb discomfort; 4, improve muscle strength and endurance of upper limbs; 5, improve quality of life; 6, limit activity (e.g., daily activities); 7, regulate emotional function; 8, enhance self-care and cognition; 9, increase self-management; and 10, reduce physical activity level.

\section{Lung rehabilitation effects cognitive score results}

There were 10 options in the questionnaire regarding the function of pulmonary rehabilitation as follows (5): (I) reduce the hospitalization rate and mortality rate; (II) limit exercise capacity; (III) aggravate dyspnea and lower limb discomfort; (IV) improve muscle strength and endurance of upper limbs (6,7); (V) improve quality of life (8); (VI) limit activity (e.g., daily activities); (VII) regulate emotional function (9-11); (VIII) enhance self-care and cognition; (IX) increase self-management; and (X) reduce physical activity level. Of these, I, IV, V, VII, VIII, and XI were correct options, and II, III, VI, and X were incorrect options. One point was given for each correct answer. The results are shown in Figure 1.

\section{Lung rehabilitation content cognition score results}

The content of lung rehabilitation included 10 options $(12,13)$ : (I) exercise (1); (II) respiratory muscle exercise; (III) home oxygen therapy; (IV) health education; (V) traditional Chinese medicine rehabilitation; (VI) telemedicine rehabilitation (e.g., rehabilitation through Internet, apps, WeChat platform); (VII) neuromuscular electrical stimulation (14); (VIII) non-invasive ventilation (15); (IX) self-management (medication adherence, diet therapy and changing bad habits and behaviors); and (X) psychological intervention. To determine whether nursing staff knew about the 10 items, 1 point was given for each item. The results are shown in Figure 2. 


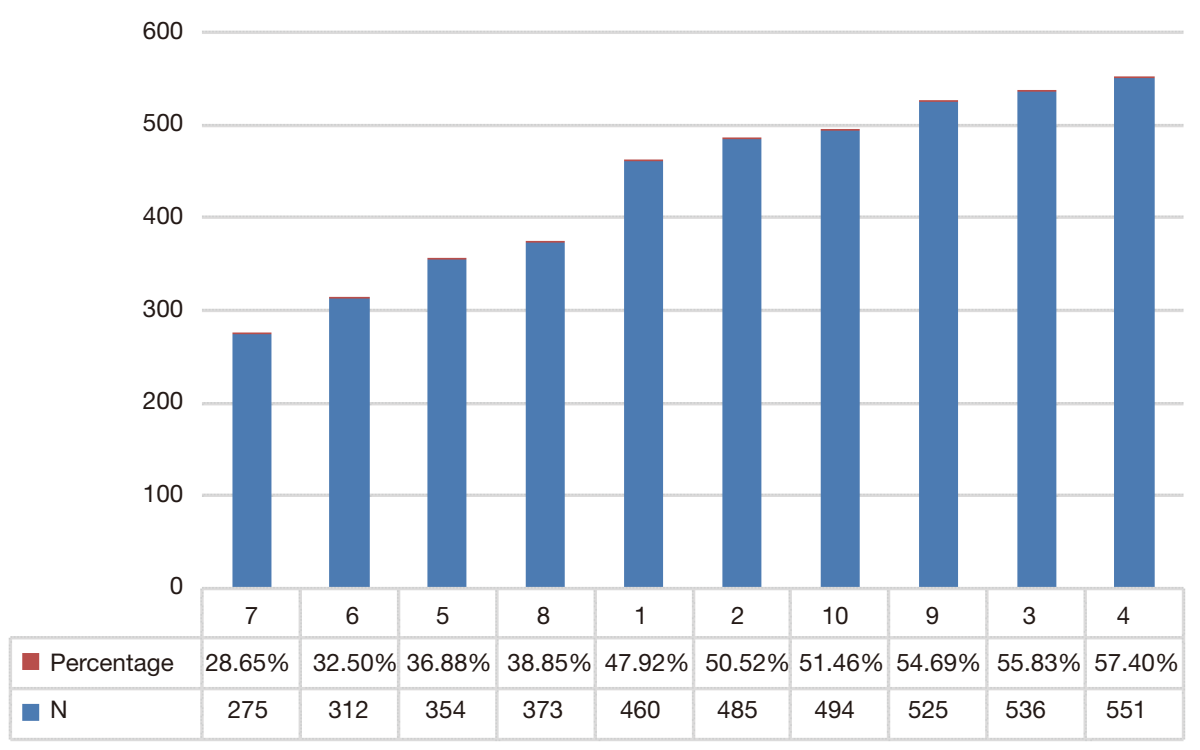

Figure 2 Number and percentage of nurses with correct cognition of lung rehabilitation content in Shanghai. 1, exercise; 2, respiratory muscle exercise; 3 , home oxygen therapy; 4, health education; 5, traditional Chinese medicine rehabilitation; 6 , telemedicine rehabilitation (e.g., rehabilitation through Internet, apps, WeChat platform); 7, neuromuscular electrical stimulation; 8, non-invasive ventilation; 9 , selfmanagement (medication adherence, diet therapy and changing bad habits and behaviors); and 10, psychological intervention.

\section{Lung rehabilitation indications cognitive score results}

Indications of lung rehabilitation included 10 options (16): (I) COPD; (II) bronchial asthma; (III) chronic bronchitis; (IV) pulmonary hypertension/cor pulmonale; (V) interstitial lung disease; (VI) bronchiectasis; (VII) lung cancer; (VIII) perioperative period of chest surgery; (IX) cardiovascular diseases; and $(\mathrm{X})$ other. For each item selected, 1 point was given. The results are shown in Figure 3.

\section{Total score of pulmonary rehabilitation knowledge results}

We performed a $\chi^{2}$-test analysis on the low and high scores of the total score of pulmonary rehabilitation knowledge. The results indicated that there were statistical differences among different groups in terms of age, education level, professional title, position, department, hospital type, hospital level, and whether they had theoretical knowledge of pulmonary rehabilitation. There were no statistical differences between different sexes. The results are shown in Table 3.

In terms of age, $136(79.5 \%)$ participants aged $\geq 40$ years achieved a high score compared with 185 (61.9\%) aged 3039 years and $241(49.2 \%)<30$ years. In terms of education level, $306(66.5 \%)$ participants with a bachelor degree or above scored higher than $256(51.2 \%)$ participants with a lower education level. In terms of professional title, $180(77.9 \%)$ nurses-in-charge scored higher than 231 nurse practitioners $(59.4 \%)$ and 151 nurses (44.4\%). In terms of positions, $88(72.7 \%)$ nurses with managerial positions scored higher than $474(56.5 \%)$ with ordinary posts. In terms of departments, 161 (71.9\%) nurses from pulmonary rehabilitation-related departments had higher scores compared with 147 (57.6\%) from general or general internal medicine departments and 254 (52.8\%) from other departments. In terms of hospital type, 71 (71.7\%) nurses from respiratory hospitals scored higher than 358 (58.6\%) nurses from general hospitals and 133 (53.2\%) from other specialized hospitals. In terms of hospital grade, 205 (55.6\%) nurses from first-grade hospitals scored lower than 154 (65.5\%) from third-grade hospitals and $203(57.0 \%)$ from second-grade hospitals. In total, $174(79.5 \%)$ nurses had studied pulmonary rehabilitation theory compared with 388 (52.4\%) who had not studied this.

\section{Logistic regression analysis results of main influencing factors of pulmonary rehabilitation knowledge score}

On the basis of the univariate analysis, the variables with 


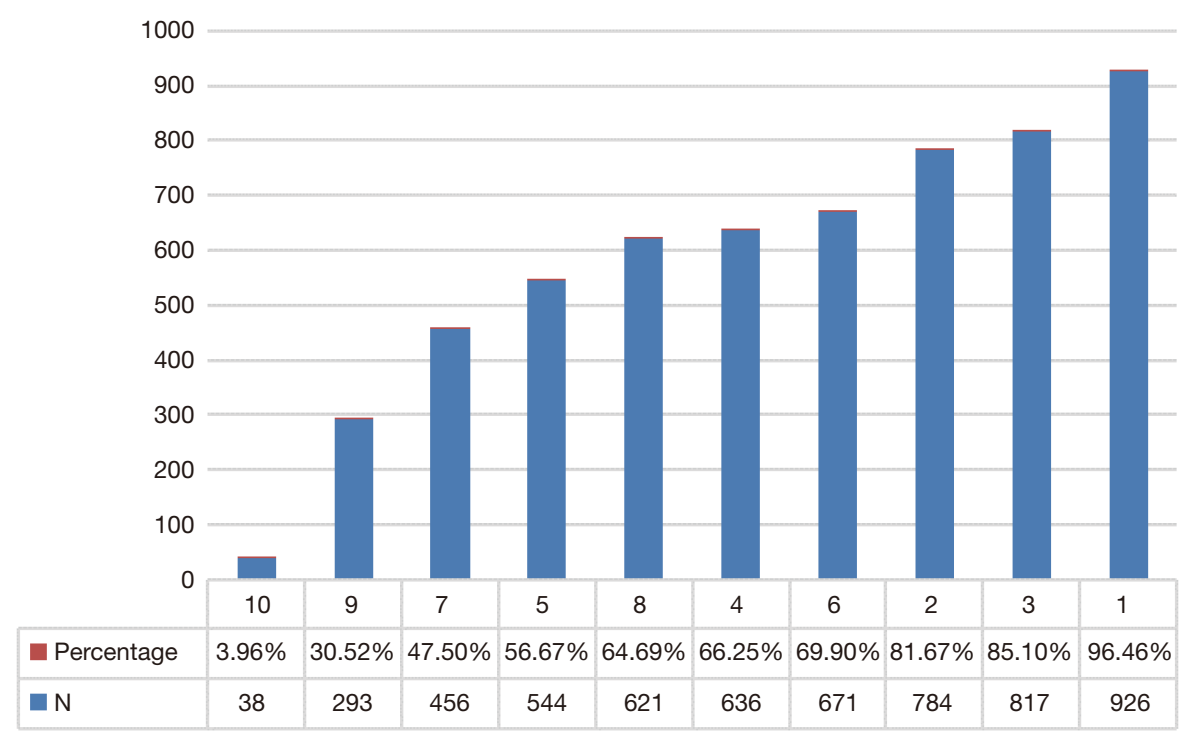

Figure 3 Number and percentage of correct cognition of lung rehabilitation indications among nurses in Shanghai. 1, chronic obstructive pulmonary disease; 2, bronchial asthma; 3, chronic bronchitis; 4, pulmonary hypertension/cor pulmonale; 5, interstitial lung disease; 6, bronchiectasis; 7, lung cancer; 8 , perioperative period of chest surgery; 9 , cardiovascular diseases; and 10, other.

statistical significance were screened out as follows: age ( $1=<30$ years, $2=30-39$ years, $3=\geq 40$ years), hospital type $(1=$ other specialized hospitals, $2=$ general hospitals, $3=$ respiratory specialized hospitals), hospital grade ( $1=$ firstlevel referral hospitals, $2=$ second-level hospitals, $3=$ thirdlevel hospitals), education level ( $1=$ college degree, $2=$ bachelor or above), professional title ( $1=$ nurse, $2=$ nurse practitioner, $3=$ nurse-in-charge or above), position $(1=$ general position, $2=$ managerial position), department $(1=$ other department, $2=$ internal or general medicine, $3=$ pulmonary rehabilitation-related department), and theoretical knowledge of lung rehabilitation $(0=$ no knowledge, $1=$ knowledge). Taking these variables as independent variables, reference category as the first, and lung rehabilitation knowledge score as the dependent variable ( $0=$ low score, $1=$ high score), logistic regression analysis was carried out. Five main factors influencing score were obtained: age $(\mathrm{P}<0.05)$, education level $(\mathrm{u}=0.351, \mathrm{P}<0.05)$, professional title $(\mathrm{P}<0.05)$, discipline $(\mathrm{P}<0.05)$, and theoretical knowledge of lung rehabilitation $(\beta=1.315, \mathrm{P}<0.001)$ (Table 4). In Table 4, age [1] referred to the comparison between nurses who were 30-39 years and $<30$ years $(\beta=-0.027, \mathrm{P}>0.05)$; age [2] referred to the comparison between nurses who were $>40$ years and $<30$ years $(\beta=0.789, \mathrm{P}<0.05)$. Professional title [1] referred to the comparison between nurse and nurse practitioner
( $\beta=0.434, \mathrm{P}<0.05)$; professional title [2] referred to the comparison between nurse and nurse-in-charge or above $(\beta=0.928, \mathrm{P}<0.01)$. Discipline [1] referred to the comparison between general or general internal medicine and other departments $(\beta=0.180, \mathrm{P}>0.05)$; discipline [2] referred to the comparison between pulmonary rehabilitation-related departments and other departments $(\beta=0.572, \mathrm{P}<0.05)$.

\section{Discussion}

We conducted a survey and analysis of pulmonary rehabilitation cognition for nursing staff in various hospitals in Shanghai by using a questionnaire survey, which mainly included the function of lung rehabilitation, the content of lung rehabilitation, and the indications of lung rehabilitation, so as to understand the degree of cognition of pulmonary rehabilitation among nurses in Shanghai, and to provide relevant data and a basis for further strengthening the work of lung rehabilitation and popularization of education. The results showed that the average score of pulmonary rehabilitation knowledge among nursing staff in Shanghai was 18.48 , the standard deviation was 5.920, and the median score was 19 . Of these nurses, 562 achieved high scores, accounting for $58.5 \%$ of the total number of respondents. This result suggests that the overall level of pulmonary rehabilitation knowledge and cognition 
Table 3 Results of $\chi^{2}$-test on the total score of pulmonary rehabilitation knowledge of nurses in Shanghai (n=960)

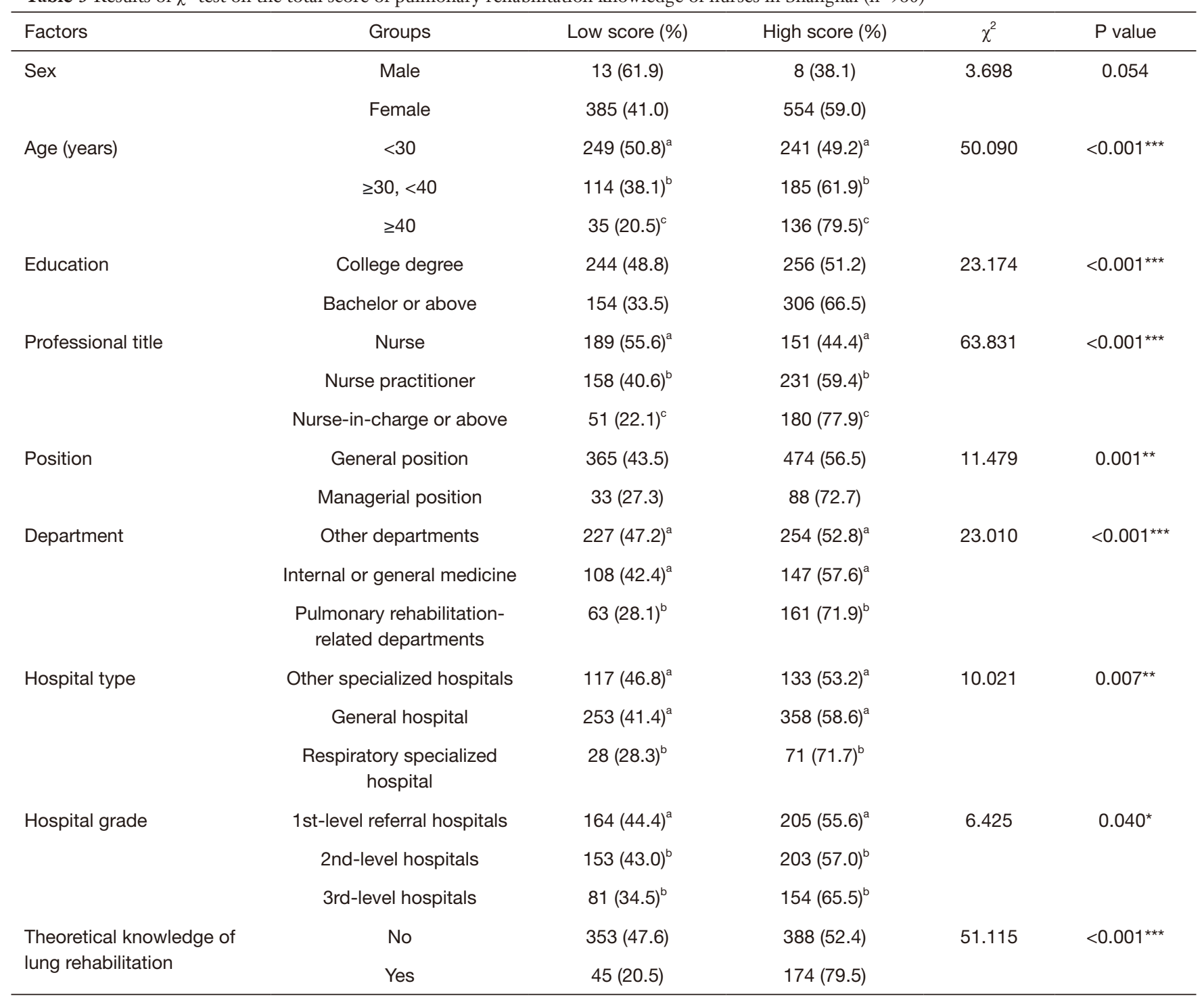

If superscript letters are the same between any two groups, the difference between the groups is not statistically significant; if the letters are different between two groups, the difference between the groups is statistically significant. ${ }^{*}, \mathrm{P}<0.05 ;{ }^{* *}, \mathrm{P}<0.01 ;{ }^{* * *}, \mathrm{P}<0.001$.

of Shanghai nurses is relatively high, but the average or median score is not high enough, and there is still room for improvement. In addition, nurses in Shanghai had the best cognitive level of pulmonary rehabilitation function, while the cognitive level of pulmonary rehabilitation content was poor. If nurses and other pulmonary rehabilitation team members do not have sufficient knowledge of lung rehabilitation, the implementation of lung rehabilitation will be difficult and the compliance of patients will be reduced.

\section{Cognitive level of Shanghai nurses on the function of pulmonary rehabilitation was generally bigh}

The average score of pulmonary rehabilitation function was 7.91 points, the median was 9 points, and the number of nurses with high scores was 849 , accounting for $88.4 \%$ of the total. There is a lot of evidence to support the effect of lung rehabilitation for COPD patients, and lung rehabilitation is an essential part of COPD management. The effects of pulmonary rehabilitation include reducing hospitalization, reducing unplanned visits, improving 
Table 4 Logistic regression analysis results of influencing factors of pulmonary rehabilitation knowledge score

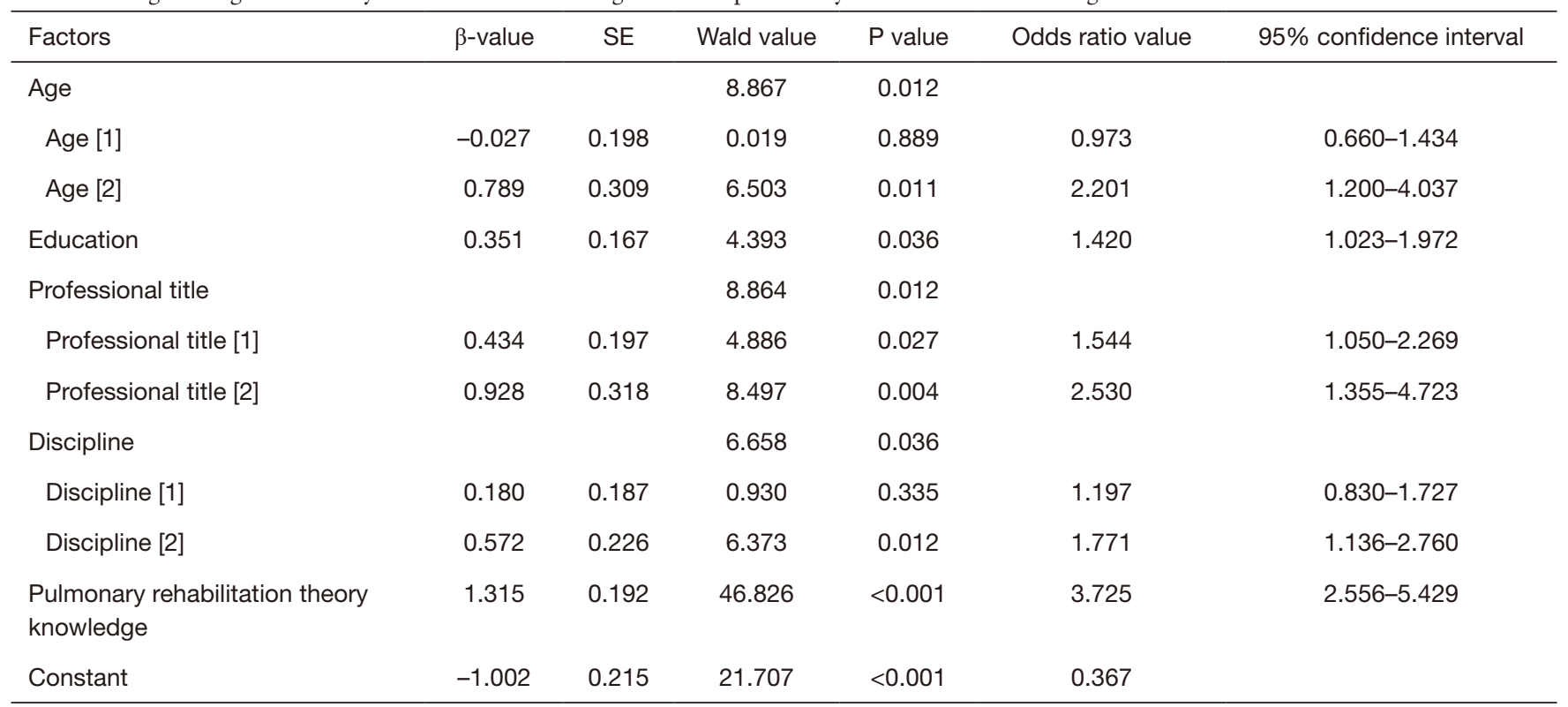

Age [1]: 30-39 vs. $<30$ years; age [2]: $>40$ vs. $<30$ years. Professional title [1]: nurse vs. nurse practitioner; professional title [2]: nurse vs. nurse-in-charge or above. Discipline [1]: general or general internal medicine vs. other departments; discipline [2]: pulmonary rehabilitationrelated departments vs. other departments. SE, standard error.

exercise ability, relieving symptoms of dyspnea and leg discomfort, improving limb muscle strength and endurance, improving health-related quality of life, improving functional ability (e.g., daily living activities), improving emotional function, enhancing self-efficacy and knowledge, and strengthening collaborative self-efficacy management with the potential to increase the level of daily physical exercise (5). In a 2016 meta-analysis, Puhan et al. noted that lung rehabilitation is an effective intervention measure for COPD patients with aggravation (17), and has a significant impact in the improvement of health-related quality of life and exercise ability. They found that the impact on readmission in hospital was statistically significant, but there was heterogeneity among the studies they analyzed. Depression is an important risk factor for readmission. Pulmonary rehabilitation has been found to improve depressive symptoms of patients with depression (18). According to the survey results of 10 items of pulmonary rehabilitation, the correct rate of improving the quality of life and increasing self-management was more than $90 \%$, which indicated that nurses had a good understanding of these functions. The correct answer rate for improving muscle strength and endurance of upper limbs was $68.96 \%$, and that of reducing physical activity level was $78.23 \%$, which was relatively low. The correct rate of other options was greater than $80 \%$.

\section{Cognitive level of Shanghai nurses on pulmonary rehabilitation content was generally low}

In the present study, the cognitive score of lung rehabilitation content was calculated according to whether they knew a certain content. The findings indicated that the understanding rate of 10 items was low. The average score of lung rehabilitation content was 4.55 , with a median of 4 . In total, 418 nurses had high scores, accounting for $43.5 \%$ of the total. Liu et al. conducted a survey on physicians, therapists, nursing staff, and rehabilitation therapists and found that the content of lung rehabilitation in China includes respiratory muscle training, sputum suction guidance and airway humidification therapy, sports rehabilitation, psychological rehabilitation, and other rehabilitation treatments, including nutrition rehabilitation, vocal music, and traditional Chinese medicine (19). The popularity of this content was $91.08 \%, 81.53 \%, 80.57 \%$, $66.88 \%$, and $14.97 \%$, respectively. According to the survey results of Chen et al., the overall knowledge of pulmonary rehabilitation knowledge of respiratory specialists in Shanghai is relatively low (4). The average answer rate of single-choice questions was less than $65 \%$, while the 
answer rate of multiple-choice questions was only $35 \%$. The survey conducted by Wang et al. found that $71.9 \%$ of general practitioners in the Jiading District of Shanghai had an understanding of the main content of COPD pulmonary rehabilitation, but the overall accuracy rate was also low for specific suitable exercise items and muscles that need to be exercised, which were $30.8 \%$ and $39.8 \%$, respectively (20). The results of the present study showed that the awareness rate of nurses on neuromuscular electrical stimulation, telemedicine rehabilitation, traditional Chinese medicine rehabilitation, non-invasive ventilation, and exercise was less than $50 \%$. There are still many medical staff in Shanghai who do not know enough about lung rehabilitation and lack relevant training. Our results show that nurses have a high awareness rate of health education (57.4\%), which may be related to the frequent education of patients at work. The content of health education includes introduction of the respiratory system and lung rehabilitation knowledge, smoking cessation, emotional management, healthy diet, effective expectoration method, correct use of inhalation devices, and prevention of infection (12). Nursing staff should have sufficient knowledge in order to carry out relevant health education for patients who require pulmonary rehabilitation. Exercise training is an important part of lung rehabilitation. It is carried out in cooperation with other methods, such as drug therapy and non-invasive ventilation, to maximize the effect of lung rehabilitation (12). Therefore, it is suggested that all nursing staff in relevant departments of pulmonary rehabilitation should strengthen their learning and practical application of this content. Ding et al.'s meta-analysis showed that remote rehabilitation improves the lung function and quality of life of patients, and could promote disease recovery and strengthen the self-management ability of patients (21). In addition, Maddocks et al. found that 6-week neuromuscular electrical stimulation can improve the functional exercise ability of patients with severe COPD by increasing the muscle quality and function of quadriceps femoris (22). The results suggest that most nursing staff only have some common knowledge of pulmonary rehabilitation, and generally have insufficient knowledge of more specialized and diversified pulmonary rehabilitation content.

\section{Cognitive level of lung rebabilitation indications of nurses in Shanghai was fair, but polarization was obvious}

The average score of lung rehabilitation indications was 6.03 , with a median of 6 . Of the patients, 532 had high scores, accounting for $55.4 \%$ of the total. Although the main indication of lung rehabilitation is COPD, it is not limited to COPD. Lung rehabilitation is not only related to respiratory medicine but to many other departments. The scope of application includes not only primary respiratory dysfunction caused by chronic respiratory diseases but also secondary respiratory dysfunction. The 2007 guidelines emphasize that pulmonary rehabilitation can be suitable for any individual with chronic respiratory disease (23). There is ample evidence that such interventions are beneficial regardless of baseline age and disease severity, although many people are not referred until late stages of the disease. The 2013 American Thoracic Society/European Respiratory Society consensus also noted that pulmonary rehabilitation for patients with dyspnea caused by nonCOPD pulmonary diseases, such as asthma, bronchiectasis, cystic fibrosis, interstitial lung disease, pulmonary hypertension, lung tumor, lung volume reduction surgery, and lung transplantation, can significantly improve the symptoms, exercise tolerance, and quality of life of patients (1). The survey results of lung rehabilitation indications in the present study showed that, of the 10 indications, the correct rate of common respiratory diseases, such as COPD, chronic bronchitis, and asthma was relatively high, all above $80 \%$, especially for COPD, which was $96.46 \%$. The correct rate for cardiovascular diseases $(30.52 \%)$ and other diseases (3.96\%) was very low, indicating that knowledge of lung rehabilitation for extrapulmonary diseases, such as cardiovascular diseases and other diseases, such as selective neuromuscular diseases and chest wall diseases, is insufficient (2).

We compared and analyzed the scores of pulmonary rehabilitation knowledge and found that, with the exception of sex, there were significant differences in the scores of nurses with different age, education level, professional title, position, department, hospital type, hospital grade, and whether they had learned knowledge of lung rehabilitation. Multivariate logistic regression analysis showed that age, education level, professional title, discipline, and theoretical knowledge of lung rehabilitation were the main factors influencing the score of pulmonary rehabilitation knowledge of nursing staff in Shanghai $(\mathrm{P}<0.05)$. In terms of age, most nurses obtained high scores, which may be due to their experience and working years. In terms of different education levels, nurses with a bachelor degree or above obtained high scores. In terms of professional titles, many nurses-in-charge or above obtained high scores. Those with high professional titles appear to 
have more relevant knowledge than those who do not. In terms of disciplines, nurses of pulmonary rehabilitationrelated departments got higher scores because they received more rehabilitation knowledge and training. This is consistent with the survey results of Liu et al. in 2016, which showed that departments carrying out lung rehabilitation in China mainly focus on respiratory medicine, followed by rehabilitation department (19). However, our survey found that the number of nurses who have theoretical knowledge lung rehabilitation is relatively small, which also leads to the general lack of knowledge of lung rehabilitation content. It is necessary to increase training, publicity, and various learning opportunities to encourage more nurses to understand the importance of lung rehabilitation knowledge.

The present study has some limitations. The number of male nursing staff we investigated was relatively small, which can impact the results of the sex comparison. The scale research of pulmonary rehabilitation knowledge level for medical staff was relatively lacking. Our questionnaire was mainly based on the guidelines and consensus of the relevant knowledge points, which reflected the cognitive level of lung rehabilitation knowledge of the respondents. A more comprehensive and reliable questionnaire needs to be developed by in the future.

In conclusion, the present study shows that there is still room for improvement in the cognitive level of pulmonary rehabilitation knowledge among nurses in Shanghai, especially nurses who are younger, have a low professional title, and work at low-level medical institutions. To ensure the smooth implementation of pulmonary rehabilitation, close cooperation between multiple departments, such as respiratory, thoracic surgery, rehabilitation, intensive care unit, nursing, and nutrition department, is required. It is suggested that relevant units should organize more multidisciplinary team discussions, teach basic and advanced pulmonary rehabilitation, print relevant learning brochures, publicize knowledge of pulmonary rehabilitation using an official WeChat account, and encourage medical staff to actively develop pulmonary rehabilitation knowledge and participate in pulmonary rehabilitation work, so as to provide patients with high-level pulmonary rehabilitation medical services.

\section{Acknowledgments}

Funding: This study was supported by the National Key Research and Development Program of China (No.
2018YFC1313604) and the Interdisciplinary Program of Shanghai Jiao Tong University (No. YG2019QNA51).

\section{Footnote}

Reporting Checklist: The authors have completed the SURGE reporting checklist. Available at http://dx.doi. org/10.21037/apm-21-190

Data Sharing Statement: Available at http://dx.doi. org/10.21037/apm-21-190

Conflicts of Interest: All authors have completed the ICMJE uniform disclosure form (available at http://dx.doi. org/10.21037/apm-21-190). The authors have no conflicts of interest to declare.

Ethical Statement: The authors are accountable for all aspects of the work in ensuring that questions related to the accuracy or integrity of any part of the work are appropriately investigated and resolved. This study was conducted in accordance with the ethical principles of the World Medical Association's Declaration of Helsinki (as revised in 2013) and was approved by the Ethics Committee of Shanghai Chest Hospital (Ethics number: KS1924). Informed consent was obtained from all patients.

Open Access Statement: This is an Open Access article distributed in accordance with the Creative Commons Attribution-NonCommercial-NoDerivs 4.0 International License (CC BY-NC-ND 4.0), which permits the noncommercial replication and distribution of the article with the strict proviso that no changes or edits are made and the original work is properly cited (including links to both the formal publication through the relevant DOI and the license). See: https://creativecommons.org/licenses/by-nc-nd/4.0/.

\section{References}

1. Spruit MA, Singh SJ, Garvey C, et al. An official American Thoracic Society/European Respiratory Society statement: key concepts and advances in pulmonary rehabilitation. Am J Respir Crit Care Med 2013;188:e13-e64.

2. Xie Y, Lu X, Duan Y, et al. Development of pulmonary rehabilitation and future prospect. West China Med J 2019;34:498-502.

3. Zhang W, Chen W, Yu B, et al. Investigation of Bristol Chronic Obstructive Pulmonary Disease Knowledge 
Questionnaire for Rehabilitation Professionals. Chin J

Rehabil Theory Pract 2011;17:390-2.

4. Chen X, Jin X, Li M, et al. Knowledge Level about Pulmonary Rehabilitation: A Questionnaire Analysis in Respiratory Physicians in Shanghai. Chin J Respir Crit Care Med 2012;11:375-7.

5. Rochester CL, Vogiatzis I, Holland AE, et al. An Official American Thoracic Society/European Respiratory Society Policy Statement: Enhancing Implementation, Use, and Delivery of Pulmonary Rehabilitation. Am J Respir Crit Care Med 2015;192:1373-86.

6. Franssen FM, Broekhuizen R, Janssen PP, et al. Effects of whole-body exercise training on body composition and functional capacity in normal-weight patients with COPD. Chest 2004;125:2021-8.

7. Spruit MA, Gosselink R, Troosters T, et al. Resistance versus endurance training in patients with COPD and peripheral muscle weakness. Eur Respir J 2002;19:1072-8.

8. Puhan MA, Gimeno-Santos E, Scharplatz M, et al. Pulmonary rehabilitation following exacerbations of chronic obstructive pulmonary disease. Cochrane Database Syst Rev 2011;(10):CD005305.

9. Emery CF, Leatherman NE, Burker EJ, et al. Psychological outcomes of a pulmonary rehabilitation program. Chest 1991;100:613-7.

10. Emery CF, Schein RL, Hauck ER, et al. Psychological and cognitive outcomes of a randomized trial of exercise among patients with chronic obstructive pulmonary disease. Health Psychol 1998;17:232-40.

11. Harrison SL, Greening NJ, Williams JEA, et al. Have we underestimated the efficacy of pulmonary rehabilitation in improving mood? Respir Med 2012;106:838-44.

12. Zhou M, Zhao J. Methods of modern pulmonary rehabilitation. Chin J Pract Intern Med 2018;38:410-3.

13. Sun D. Research progress of pulmonary rehabilitation for chronic obstructive pulmonary disease. Chin J Pract Intern Med 2018;38:414-6.

14. Sillen MJH, Speksnijder CM, Eterman R-MA, et al. Effects of neuromuscular electrical stimulation of muscles

Cite this article as: Zhang H, Song Y, Mao X, Pan F, Pan Y, Jiang L. Cognitive status of nurses in Shanghai on pulmonary rehabilitation. Ann Palliat Med 2021;10(2):2184-2194. doi: 10.21037/apm-21-190 of ambulation in patients with chronic heart failure or COPD: a systematic review of the English-language literature. Chest 2009;136:44-61.

15. Chen H, Zhao S. Application of non-invasive positive pressure ventilation in the pulmonary rehabilitation of chronic obstructive pulmonary disease. Chin J Pract Intern Med 2018;38:417-20.

16. Zheng Z, Hu J, Liu N. Progress in the research of respiratory rehabilitation therapy 2017. Chin J Pract Intern Med 2018;38:393-6.

17. Puhan MA, Gimeno-Santos E, Cates CJ, et al. Pulmonary rehabilitation following exacerbations of chronic obstructive pulmonary disease. Cochrane Database Syst Rev 2016;12:CD005305.

18. Coventry PA, Hind D. Comprehensive pulmonary rehabilitation for anxiety and depression in adults with chronic obstructive pulmonary disease: Systematic review and meta-analysis. J Psychosom Res 2007;63:551-65.

19. Liu N, Zheng Z, Hu J, et al. A nation wide online questionnaire survey on pulmonary rehabilitation in China in 2016. Int J Respiration 2018;38:114-7.

20. Wang Y, Tu C, Wan X, et al. Investigation of awareness level of general doctors about chronic obstructive pulmonary disease in Jiading District, Shanghai. J Clin Pulm Med 2019;24:1775-80.

21. Ding $M, H u$, Shen Q, et al. Remote rehabilitation applied in patients with stable stage of chronic obstructive pulmonary disease: a meta-analysis. Chin J Tissue Eng Res 2020;24:1306-12.

22. Maddocks M, Nolan CM, Man WDC, et al. Neuromuscular electrical stimulation to improve exercise capacity in patients with severe COPD: a randomised double-blind, placebo-controlled trial. Lancet Respir Med 2016;4:27-36.

23. Ries AL, Bauldoff GS, Carlin BW, et al. Pulmonary Rehabilitation: Joint ACCP/AACVPR Evidence-Based Clinical Practice Guidelines. Chest 2007;131:4S-42S.

(English Language Editor: R. Scott) 